\title{
Article
}

\section{Experiences of Mentors Training Underrepresented Undergraduates in the Research Laboratory}

\author{
Amy J. Prunuske, ${ }^{*}$ Janelle Wilson, ${ }^{\dagger}$ Melissa Walls, ${ }^{*}$ and Benjamin Clarke ${ }^{*}$ \\ ${ }^{*}$ University of Minnesota Medical School and ${ }^{\dagger}$ University of Minnesota-Duluth, Duluth, MN 55812
}

Submitted March 3, 2013; Revised May 24, 2013; Accepted June 18, 2013

Monitoring Editor: Deborah Allen

\begin{abstract}
Successfully recruiting students from underrepresented groups to pursue biomedical science research careers continues to be a challenge. Early exposure to scientific research is often cited as a powerful means to attract research scholars with the research mentor being critical in facilitating the development of an individual's science identity and career; however, most mentors in the biological sciences have had little formal training in working with research mentees. To better understand mentors' experiences working with undergraduates in the laboratory, we conducted semistructured interviews with 15 research mentors at a public university in the Midwest. The interviewed mentors were part of a program designed to increase the number of American Indians pursuing biomedi$\mathrm{cal} /$ biobehavioral research careers and represented a broad array of perspectives, including equal representation of male and female mentors, mentors from underrepresented groups, mentors at different levels of their careers, and mentors from undergraduate and professional school departments. The mentors identified benefits and challenges in being an effective mentor. We also explored what the term underrepresented means to the mentors and discovered that most of the mentors had an incomplete understanding about how differences in culture could contribute to underrepresented students' experience in the laboratory. Our interviews identify issues relevant to designing programs and courses focused on undergraduate student research.
\end{abstract}

\section{INTRODUCTION}

The diversity of the U.S. population is not reflected in its current biomedical workforce. For American Indian/Alaskan Native (AI/AN) students, the rates at which students start an undergraduate degree are similar to those seen for white students, but the attrition rates have been reported to be as high as $85 \%$, and $\mathrm{AI} / \mathrm{AN}$ is the racial ethnic group least likely to major in science and engineering (Guillory, 2008). James et al. (2012) note that "attrition from health science pathways can be expected owing to competition from other fields, particularly disciplines that require less time in school or are

DOI: $10.1187 /$ cbe.13-02-0043

Address correspondence to: Amy Prunuske (aprunusk@d.umn.edu).

(C) 2013 A. Prunuske et al. CBE-Life Sciences Education (c) 2013 The American Society for Cell Biology. This article is distributed by The American Society for Cell Biology under license from the author(s). It is available to the public under an AttributionNoncommercial-Share Alike 3.0 Unported Creative Commons License (http:/ / creativecommons.org/licenses/by-nc-sa/3.0).

"ASCB ${ }^{\circledR}$ " and "The American Society for Cell Biology ${ }^{\circledR}$ " are registered trademarks of The American Society for Cell Biology. perceived to have more immediate or greater financial payoff than health and science careers"(p. 474). Additional challenges faced by these students include a lack of role models, added pressure associated with being the only individual of their race in a program, and social isolation (Burgess, 2012). Of the 87,790 science and engineering doctorates awarded from 2005 to 2009, only 313 were awarded to AI/AN students (National Science Board, 2012).

The lack of a racially and ethnically diverse student population in the sciences is troubling for several reasons. There are significant health disparities in this country, and we need a diverse and innovative research community to help identify and address these problems (U.S. Department of Health and Human Services, 2005). In addition, many National Institutes of Health-funded projects are interested in comparisons between racial and ethnic groups, which must be done in a way that is respectful of the individuals involved and with their representation at the table (Schroeder et al., 2006).

In recent years, the federal government has invested half a billion dollars per year to fund programs whose primary goal is to support underrepresented students in obtaining postsecondary science, technology, engineering, and mathematics (STEM) degrees (National Science and Technology 
Council, 2011). Many of the programs incorporate a mentored undergraduate research experience, which has been shown to increase the likelihood of students enrolling in graduate school (National Research Council, 2005; Eagan et al., 2013). The laboratory experience gives students the opportunity to develop important research and communication skills (Lopatto, 2004). Additional benefits include helping the students to feel comfortable in the academic environment and to build their professional networks (Hunter et al., 2007). In addition to the financial support these programs provide, the sense of belonging acts to support student integration and retention (Villarejo et al., 2008). The success of these undergraduate research programs depends not only on the director of the program but also on the mentors working directly with the students in the laboratory.

Most laboratory mentor-mentee relationships are centered on the mentor-protégé or dyadic model. While we know that mentoring is important for career progression, there are limited studies as to how mentors should support underrepresented mentees as they navigate the academic culture, and evidence suggests that poor mentorship contributes to losses of minority students at each level of education (James et al., 2012). Science identity theory supports a major role for mentors in helping mentees to develop scientific knowledge competence, to learn to practice science, and in recognizing mentees as scientists (Carlone and Johnson, 2007). By exploring mentors' attitudes, expectations, and experiences, we hoped to learn more about how mentors contribute to science identity formation in their mentees. In addition, culture contributes to scientific identity, and we wanted to explore with the mentors how the needs of underrepresented students might be somewhat different from those in the majority group. While there is a good body of research focused on mentees, we believe that turning more attention to the mentors who are providing the mentoring to students is necessary in attempting to more fully understand the mentormentee relationship and identifying how that relationship can be strengthened.

\section{METHODS}

\section{Participants}

Our sample of mentors constitutes a purposive sample, that is, the subjects were selected based on their participation in mentoring programs designed to increase the enrollment in graduate school of students from underrepresented groups in science. These programs have been running at the University of Minnesota-Duluth for the past $15 \mathrm{yr}$, and their primary target population is AI undergraduate students. The current program, Pathways to Advanced Degrees in Life Sciences (www.d.umn.edu/brpa), enrolls eight students per year (Box 1). Students enrolled in the program participate in a research education program designed to help students develop science process skills, following which students participate in a multiyear mentored research experience.

The interviewed mentors had been at the institution for anywhere from 1 to $46 \mathrm{yr}$ and were from medicine and pharmacy professional schools and from biology and chemistry undergraduate departments. Among participants in our sample, several academic ranks were represented: three were at
Box 1. Description of current Pathways to Advanced Degrees in Life Sciences program.

\author{
A. Summer Workshops \\ 1. Laboratory and Hygiene Skills \\ 2. Responsible Conduct in Research \\ 3. Quantitative Methods \\ 4. Problem-Based Learning \\ 5. Professional Writing \\ 6. Computer Modeling \\ 7. Survival in Academics
}

B. 2-year mentored research experience

the rank of professor, seven at the rank of associate professor, and two at the rank of assistant professor; three were graduate students. The sample included seven female and eight male mentors.

\section{Interviews}

The University of Minnesota Institutional Review Board approved the research protocol (study number: 1202S09842). The mentors were contacted by the program director regarding participation in an interview, and all of the mentors agreed to participate. Prior to the interview, each participant provided consent and answered a series of demographic questions. The two primary researchers, one with experience in qualitative research and one with experience in laboratory research, conducted all of the interviews. Employing a semistructured interview style, our interview schedule was such that we asked primarily open-ended questions, and we let participants direct the flow of "conversation," even if that meant we diverged from the interview schedule for a period of time. The interview script that was used can be found in the Supplemental Material. The interviewers ended by asking whether there were any additional comments the mentor would like to share to enable the researchers to better understand his or her mentorship experience. Interviews ranged in duration from 40 to $90 \mathrm{~min}$.

\section{Data Analysis}

The interviews were audio-recorded, transcribed, and then independently coded by a white social scientist (J.W.), a white biomedical researcher (A.P.), and an AI biobehavioral researcher (M.W.). The coders used an inductive approach for initial open coding, organization, and notation of the data (Creswell, 1994; Lofland et al., 2005), attempting to ascertain participants' subjective experiences as mentors in the program. That is, we attempted to identify thematic trends in the data independent of theoretical organizing frameworks. The coders used constant comparisons to look for emergent themes, and the interrater reliability was found to be high (more than $90 \%$ ). While the three coders may have originally labeled particular categories differently, once we discussed the codes, we discovered that our meanings were the same, with slightly different wording. Following this open-coding procedure, we used a focused-coding strategy to organize initial themes within the context of existing literature. The focused-coding process 
also allowed us to directly identify meaningful transcript excerpts and combine open-coding categories as appropriate (Charmaz, 2006).

Our key objective was to use a phenomenological approach to ascertain participants' subjective experiences as mentors in the program, and we believe a qualitative approach is the most appropriate, given the depth of the data generated and the possibility for contextual and nuance interpretation. While our findings cannot be generalized, given our small sample size, they are likely to transferable to individuals in comparable situations (Lincoln and Guba, 1985). We achieved saturation after 15 interviews, and this is supported by data from Guest et al. (2006) suggesting that saturation is possible with 12 interviews.

\section{RESULTS}

To learn more about mentors' experiences working with underrepresented students in the research laboratory, we contacted (through the program director) 15 mentors, and all of the mentors agreed to participate in an interview. The mentors' research focuses included a wide range of disciplines: cell biology, biochemistry, ecology, plant evolutionary genetics, medicinal chemistry, physiology, and pharmacology (Table 1), and the average size of the mentors' research groups was 7.6 individuals. The informants were at different points in their careers, representing graduate students through full professors, but all were directly involved in mentoring undergraduates. The mentors were equally divided by gender; 13 of our informants self-identified as white/non-Hispanic, and two self-identified as AI.

A great deal of information was gained from these interviews, and we wish to provide a descriptive account of key themes that emerged in the interview data. Mentors described how they envision their role as mentors and how that shapes the mentoring relationship. We learned what the mentors see as the primary advantages, as well as the disadvantages, for themselves and their mentees. Informants were asked to describe how they conceptualize the term "underrepresented" and to identify ways in which diversity affects the mentoring relationship. Mentors also shared their views on what they envision for their mentees' futures. We address each of these themes below, and in so doing, we pay particular attention to the latent content of the data, that is, the meaning(s) that underlie the manifest content.

\section{The Role and Benefits of Being a Mentor}

With respect to how the informants see their role as mentors in the program, the key theme that emerged in our interview data was providing opportunities for career developmentmore specifically, training students in lab techniques and giv-

Table 1. Demographics of mentors interviewed

\begin{tabular}{lcccc}
\hline & Biology & Chemistry & Pharmacy & Medicine \\
\hline Female & 3 & 0 & 0 & 4 \\
Male & 0 & 1 & 1 & 6 \\
Total & 3 & 1 & 1 & 10 \\
\hline
\end{tabular}

ing them experience in designing and executing experiments. Mentors highlighted enabling students to learn about science, helping them to discover their aptitudes and interests, and building students' confidence. Informants noted that students often work on faculty members' research projects, but some informants indicated they try to get the students to the point of testing their own hypotheses. The primary benefit that mentors identified for students was exposure to the scientific world and how science works-as one informant stated, "doing the scientific method from start to finish."

One respondent commented that the "strength of the program is its duration and the level of financial support." The longer duration was described as allowing students to see the "meandering pathway of learning," and the financial support enabled students to travel to meetings and interact with the larger scientific community. A sense of belonging (e.g., working on a team) was also highlighted. Many of the responses could fall under "professional socialization." One informant stated that "it's a path to graduation ... a path to success in science after graduation."

With respect to benefits that the mentors themselves experience, the most frequent responses point toward intrinsic rewards. For example, one respondent stated as a benefit: "having people who are interested in learning ... it makes the lab be alive." Another noted that working with mentees in the lab "keeps you on top of your game." Others commented on the experience of seeing the students grow and develop: "they acquire knowledge and they ... take ownership" and "knowing students leave changed for the better thanks to your interaction." Some mentors participated in the program to support a colleague's worthwhile program and/or to give back to the scientific community, because their own undergraduate research experience was formative in their career development.

Respondents were asked what is needed for one to be an effective mentor. A majority of mentors indicated that the mentor needs to be involved and/or enthusiastic. One individual described this as being infectious, in that the excitement can spread to the student. A mentor needs to be able to explain, at a nonexpert level, and help the student understand how his or her project fits into the bigger picture. A mentor also needs to be able to break the project down into doable pieces and provide the students structure, "because it's a big scientific world." Respondents emphasized that mentors should not be too critical, because that may turn people off to science. It was advised that mentors be empathetic and patient, but careful to maintain an environment that is not perceived to be too relaxed.

\section{Challenges or Disadvantages of Being a Mentor}

When asked whether they could think of any challenges or disadvantages associated with serving as a mentor, the modal categories of responses were lack of recognition for mentoring undergraduate students and the time commitment required. With respect to the former, some illustrative quotes include "I don't have any objective evidence that mentoring (undergraduates) has been something that was valued by my bosses," "You don't get any recognition for that, at any level," "It's partly charity work," and "It's a career killer" (i.e., this kind of work will not get one promoted). So, the lack of recognition/reward from superiors and the time commitment were 
the two big themes, and only one mentor felt there were "none whatsoever" challenges associated with mentoring.

Other comments pointed toward challenges that stem from the academic grade level of the students; for example, it was noted that training undergraduates in the lab is a significant time commitment and may mean less research productivity potential as compared with a graduate student. There was concern that many freshmen and sophomores are relatively immature and are not accustomed to receiving constructive criticism. An informant also observed that a challenge could be that you might get a student whose personality or aptitude is not a good fit with the other members of the laboratory.

We asked the mentors whether they used any type of screening process when deciding whether to accept a student into the lab. Some factors the mentors considered included personal connection to the focus of the lab (e.g., family member with cancer), a student's ability to make a commitment, a student's comfort with killing animals, and whether the mentor felt a student had a "high level of innate intelligence." Mentors also explained that they accepted most students, and then the students would "sink or swim," which was also described as a larger process at the institution of "culling the herd," otherwise expressed as there are "just going to be people who are not going to fit." Almost all of the informants identified when the students stopped coming to lab as evidence of an unsuccessful mentoring relationship, which was generally attributed to the students discovering that science was not for them.

As a follow-up to the question about challenges or disadvantages, we asked our informants whether there might be particular programs, networking ideas, or resources they thought could support mentors at their institution. Some respondents indicated that knowing what the "best practices" are would be helpful; in particular, it was noted that it would be helpful to know whether there are different best practices for underrepresented students. Some mentors mentioned that training on how to supervise others might be instrumental, but there was concern regarding whether the mentors would have time to participate in training sessions.

\section{Mentors' Understanding of What Is Meant by "Underrepresented"}

Given that the primary goal of this particular mentoring program is to recruit and train students from underrepresented groups in higher education (AIs, in particular), one of the questions posed to informants was: "From this context, what does the term 'underrepresented' mean to you?" The modal response centered on first-generation college students and members of minority groups. One informant clarified the minority group definition to include "African Americans of slave descent [and] ... Natives, because of treaty rights." One individual mentioned older, returning students. Many felt that it was class based and indicated individuals with little experience, few opportunities, and lack of financial support. None of the informants identified disability in the context of underrepresentation.

Concomitant with considering social class and race/ethnicity, a number of informants referred specifically to representation (or rather, lack of representation) in the sciences:
People that ... are not represented in the professional ranks ... it's largely ethnicity based, but also sex-based because my understanding is that even though women are more than half of grad students in math and med school, they are still minority in faculty positions.

An evolving definition appeared to be one relating to health disparities among different groups.

\section{How Does Diversity Affect the Mentoring Relationship?}

Given our focus on, and concern about, the experience of underrepresented students in the academic setting in general, and in this mentoring program in particular, we were interested in learning how these mentors view the effect of diversity in the mentor-mentee relationship. One respondent noted that it is easier to make analogies with people who share a background similar to your own. So to the extent that the nature of a student's diversity is distinct from the mentor's, this could present a challenge. Some mentors recognized that preconceived notions can be a complicating factor and that we all need to be aware of our propensity to be influenced by stereotypes and the issue of self-fulfilling prophecies.

One of our respondents, an AI who had gone through the program as a mentee, emphasized that, from the students' side, they may feel they have entered a foreign land and may be less confident. Also, there is a difference in culture in terms of the education system, which is often viewed with criticism and suspicion, and this system is taking the AI students away from their communities. And there is a challenge with the institutional setting, wherein there is "one way to do things." This respondent did not encounter a lot of negative incidents, and she felt the program allowed students to be themselves. But the dissonance and struggle identified is important to highlight. As was stated:

\begin{abstract}
If nobody in my family had a profession where something like the sciences is familiar to me, then it becomes this foreign land, where I'm trepidatious and not comfortable, and I don't know if I belong here necessarily ... Like in my culture, it's very important to contribute and be of service to the people, but doing it through the education system, not necessarily. 'Cause well, I'm an American Indian, and so a lot of the education system is seen with criticism, with intense, like suspicion.
\end{abstract}

Another mentor expressed concern about "breaking spirit" by not being familiar with body language and culture. Many mentors expressed interest in learning from students and indicated that it creates a richer experience. Importantly, though, the majority of mentors in this study indicated that diversity did not impact their relationship at all.

\section{Mentees' Futures}

Informants were asked whether they encouraged their mentees to continue their science education and obtain a $\mathrm{PhD}$, as this is the major goal of these programs. Most mentors emphasized that the students should know their options and should be encouraged to follow what will be the right path for them, realizing that this very well may mean that they do not go on to earn advanced degrees. The following responses exemplify this: 
"In my lab I encourage them (the students) to do what they want to do."

"I definitely encourage going on to a graduate degree ... look at your options. [But] don't assume that the higher degree is gonna set you up for the best position possible. Look at what you want to do. Do you want to work in the field? Do you want to be conducting the experiment? Or do you want to be designing the experiment, and do you want to be the overseer of many projects?"

The following responses are consistent with the theme of making sure that students are aware of their options, but these comments also seem to have more of a dissuading aspect to them (i.e., dissuading students from pursuing a PhD as a way of "protecting" the students):

"I think the academic life is a very difficult one, and if they bring it up with me, I usually tell them to talk to several people and find out about ... quality of life issues."

"I don't push graduate school with any of the students because ... I think we're producing far too many PhDs in science than we are jobs."

"I used to try and make everybody a PhD, but I've come to realize that you've gotta have fire in the belly and a tough hide. And not everybody has that (p. 358)".

Such comments appear to address the concern expressed by Byars-Winston et al. (2011) and others that academic training equips students with "the technical skills for job success but provides comparatively no preparation for developing one's career, balancing work-life matters, or managing professional challenges" (p. 358). The majority of mentors in our sample were sensitive to helping ensure that students are aware of their options and, if students do pursue advanced degrees, that they do so with their eyes wide open to the realities of what this entails.

\section{DISCUSSION}

Our interviews with a group of mentors who participate in a mentoring program aimed at recruiting underrepresented students into the biomedical/biobehavioral sciences have given us insight into the mentors' perceptions and experiences. Results from our interviews identified particular challenges the mentors face and what resources they feel might be helpful. The results clearly sensitize us to the need for institutions to demonstrate that they value mentoring. Importantly, the interview data demonstrate how mentors conceptualize the meaning of underrepresentation and how they anticipate that diversity does (or does not) affect mentoring relationships.

While the small size of our sample does not readily lend itself to making claims about interactions between variables (e.g., that race and/or gender of mentor had a significant effect on the meanings mentors attached to underrepresentation or the effects of diversity), it is the case that mentors coming from underrepresented groups themselves were more sensitive to the aspect of diversity and more understanding of ways in which the academic setting may represent a strange world in which underrepresented students struggle to readily see how and where they fit.
Discovering the predominance of the notion that diversity does not affect the mentoring relationship is an important finding, and one that needs to be addressed more fully. This idea of color blindness can be problematic, in that it ignores or overlooks the experiences of those who do not hold a dominant position in society and can hinder one's ability to recognize unconscious biases (Brown et al., 2003). Members of the majority group are also conditioned to not recognize the privileges that their majority group status may bestow (McIntosh, 1989). Individuals primed with color blindness exhibit more behavioral prejudice, which was shown to mediate decreased cognitive performance of ethnic minorities (Holoien and Shelton, 2012).

Mentors in our study also had an incomplete understanding of what factors contribute to student attrition from the sciences. A multicampus study of science, math, and engineering students found that only $10 \%$ of these students left these disciplines because they had discovered that a nonscience field was a better fit for them (Seymour and Hewitt, 1997). Having coping strategies, including connections with other students, feelings of self-efficacy (Bandura, 1997), and being able to embrace more of an individualistic mentality, are key factors in determining whether students remain in the scientific discipline or choose to leave. Adapting these behaviors is often more challenging for AI students and others raised as part of collectivist societies, in which a focus is on the good of the community rather than individual performance (Guiffrida, 2006). Finally, the ability of AIs to successfully connect to the academic community may be complicated by previous historical trauma experienced by their home communities, which results in the distrust mentioned by one of the mentors in our study (Adams, 1995).

Although not an area of focus prior to beginning our study, our findings also revealed another area in which greater sensitivity is needed: addressing the killing of animals in the laboratory. One mentor stated that potential mentees are told that killing animals is a requirement to join the laboratory. This direct approach has been previously reported to shut out AI students who, on the basis of their cultural beliefs, may not be comfortable with killing animals but nevertheless could certainly have a future in the biomedical/biobehavioral sciences (Johnson, 2007). Mentors could be more empathetic in this regard and could have students participate in the analysis of a sample without being required to participate in the dissection. These types of difficulties in cross-cultural communication have been associated with students feeling isolated in the academic environment (Pololi et al., 2010).

Another important observation was the reluctance of some of the mentors to encourage undergraduate students to pursue academic careers. Similar challenges have also been identified at the national level, with fewer PhDs in tenure-track positions and a long training period with significantly less pay when compared with other advanced degrees (National Institutes of Health, 2012). For many underrepresented students, having financial stability is critical, as they often have larger undergraduate student loan debt and may need to support multiple family members (Pololi et al., 2010). Furthermore, when students look around and do not see any role models who look like them, it is often difficult for them to envision themselves as the person running the laboratory (Tanner and Allen, 2007). These are important challenges to 


\section{Box 2. Proposed mentor-training program.}

1. Transmit goals of program.

2. Build a community for the mentors.

3. Develop strategies to help students meet research goals.

4. Discuss mentor's role in supporting student's professional and personal development.

5. Increase awareness about the psychological basis of bias and stereotype threat.

6. Encourage mentors to build long term relationships with mentees and to frame their relationship as a partnership.

address if we are to meet the goal of increasing diversity within the research community.

Leadership at the departmental level needs to legitimize and support mentoring of undergraduates, so both mentors and mentees are working within a supportive environment. Many departments and institutions have diversity statements, and one way to enhance diversity is through the support of mentors, including greater recognition and mentor training. Another concern is providing faculty with the time to adequately mentor. A previous study with female undergraduates, including two AI students, suggested that students may interpret faculty lack of time as a dislike of the students, and this may discourage the students from pursuing science degrees (Johnson, 2007).

Most of the mentors expressed interest in mentor training, but some mentors were hesitant, which could be alleviated by departmental support. Box 2 highlights our recommendations for a mentor-training program based on our results. Implementing a training program will help to build a community, because many of the mentors were unaware of the identities of the other mentors associated with the program. We recommend using a mentoring program similar to Entering Mentoring (Handelsman et al., 2005), which provides guidance in building laboratory skills through an active-learning approach, but we also strongly encourage including a cultural component.

The cultural component should involve a nonthreatening environment in which the mentors can discuss that categorization leading to stereotyping is a normal part of human cognition, that stress can increase stereotyping, and that suppression of stereotypes can lead to negative, unintended consequences (Burgess et al., 2007). Mentors need to understand how stereotype threat can impair students' intellectual functioning (Aronson et al., 2013). As Claude Steele (1997) has demonstrated, when one's social identity is attached to a negative stereotype, the individual may then underperform, thus reinforcing or "fulfilling" the stereotype. Stereotype threat has been documented to occur with regard to underrepresented students in STEM fields (Hurtado et al., 2009).

A limitation of our study is that it was performed at a single institution. The themes we identified can serve as the basis for developing quantitative surveys to be applied to mentors at other institutions to test whether the identified themes are more generalizable. Dolan and Johnson (2010) suggested that the lack of professional rewards for mentoring undergraduates is not unique to our institution. It is also important to note that there is recent evidence suggesting widespread racial and gender bias among scientists during both the grant-review process and hiring (Ginther et al., 2011; Moss-Racusin et al., 2012).

The primary goal of our project is to characterize factors that affect AI students' abilities to develop science identities. As described here, we focused on the laboratory mentoring relationship from the perspective of the mentor. Sharing the knowledge gained from this study with individuals involved in mentoring should facilitate improved mentoring relationships, better enhance underrepresented students' college experience, and lay the groundwork for these students' career progression in the biomedical/biobehavioral sciences. The dominant/majority paradigms must identify ways to incorporate those perspectives that have historically been absent in the scientific workforce. Our research addresses important issues regarding diversification of the scientific enterprise-not by means of tokenism, but through a genuine, deliberate, inclusive effort by providing support, assistance, and resources to enable success.

\section{ACKNOWLEDGMENTS}

The authors appreciate the support of the additional members of the Research on Mentors in Pathways team, including Ron Regal, George Trachte, and Mary Cannedy Clarke. Funding for this project was supported by a Pathways to Advanced Degrees in Life Sciences grant (GM-086669) to B.C.

\section{REFERENCES}

Adams DW (1995). Education for Extinction: American Indians and the Boarding-School Experience, 1875-1928, Lawrence: University Press of Kansas.

Aronson J, Burgess D, Phelan SM, Juarez L (2013). Unhealthy interactions: the role of stereotype threat in health disparities. Am J Public Health 103, 50-56.

Bandura A (1997). Self-Efficacy: The Exercise of Control, New York: Freeman.

Brown MK, Carnoy M, Currie E, Duster T, Oppenheimer DB, Shultz MM, Wellman D (2003). Whitewashing Race: The Myth of a Color-Blind Society, Berkeley: University of California Press.

Burgess D (2012). iBioSeminars: Mentoring Students of Color. www.ibiomagazine.org/issues/december-2012-issue/david-burgess .html (accessed 26 February 2013).

Burgess D, van Ryn M, Dovidio J, Saha S (2007). Reducing racial bias among health care providers: lessons from social-cognitive psychology. J Gen Intern Med 22, 882-887.

Byars-Winston A, Gutierrez B, Topp S, Carnes M (2011). Integrating theory and practice to increase scientific workforce diversity: a framework for career development in graduate research training. Cell Biol Educ 10, 357-367.

Carlone HB, Johnson A (2007). Understanding the science experience of successful women of color: science identity as an analytic lens. J Res Sci Teach 44, 1187-1218.

Charmaz K (2006). Constructing Grounded Theory: A Practical Guide through Qualitative Analysis, Thousand Oaks, CA: Sage.

Creswell J (1994). Research Design: Qualitative and Quantitative Approaches, Thousand Oaks, CA: Sage.

Dolan EL, Johnson D (2010). The undergraduate-postgraduatefaculty triad: unique functions and tensions associated with undergraduate research experiences at research universities CBE Life Sci Educ 10, 543-553. 
Eagan MK Jr., Hurtado S, Chang MJ, Garcia GA (2013). Making a difference in science education: the impact of undergraduate research programs. Am Educ Res J 50, 1-31.

Ginther DK, Schaffer WT, Schnell J, Masimore B, Liu F, Haak LL, Kington R (2011). Race, ethnicity, and NIH research awards. Science 333, 1015-1019.

Guest G, Bunce A, Johnson L (2006). How many interviews are enough? An experiment with data saturation and variability. Field Methods 18, 59-82.

Guiffrida DA (2006). Toward a cultural advancement of Tinto's theory. Rev High Educ 29, 451-472.

Guillory R (2008). It's about family: Native American student persistence in higher education. J High Educ 79, 58-87.

Handelsman J, Pfund C, Lauffer SM, Pribbenow CM (2005). Entering Mentoring: A Seminar to Train a New Generation of Scientists, Madison: Board of Regents of the University of Wisconsin.

Holoien DS, Shelton JN (2012). You deplete me: the cognitive costs of colorblindness on ethnic minorities. J Exp Social Psychol 48, 562565 .

Hunter A-B, Laursen SL, Seymour E (2007). Becoming a scientist: the role of undergraduate research in students' cognitive, personal, and professional development. Sci Educ 91, 36-74.

Hurtado S, Cabrera NL, Lin MH, Arellano L, Espinosa LL (2009). Diversifying science: underrepresented student experiences in structured research programs. Res High Educ 50, 189-214.

James R, Starks H, Segrest VA, Burke W (2012). From leaky pipeline to irrigation system: minority education through the lens of community-based participatory research. Prog Community Health Partnersh 6, 471-479.

Johnson AC (2007). Unintended consequences: how science professors discourage women of color. Sci Educ 91, 805-821.

Lincoln YS, Guba EG (1985). Naturalistic Inquiry, Newbury Park, CA: Sage.

Lofland J, Snow D, Anderson L, Lofland L (2005). Analyzing Social Settings: A Guide to Qualitative Observation and Analysis, 4th ed., Belmont, CA: Wadsworth.

Lopatto D (2004). Survey of Undergraduate Research Experiences (SURE): first findings. Cell Biol Educ 3, 270-277.
McIntosh P (1989). White privilege: unpacking the invisible knapsack. Peace and Freedom, July/August, 9-10.

Moss-Racusin CA, Dovidio JF, Brescoll VL, Graham MJ, Handelsman J (2012). Science faculty's subtle gender biases favor male students. Proc Natl Acad Sci USA 109, 16474-16479.

National Institutes of Health (2012). Biomedical Research Workforce Working Group Report. http://acd.od.nih.gov/Biomedical _research_wgreport.pdf. (accessed 28 February 2013).

National Research Council (2005). Assessment of NIH Minority Research and Training Programs. www.nap.edu/catalog.php? record_id=11329 (accessed 27 February 2013).

National Science and Technology Council (2011). The Federal Science, Technology, Engineering, and Mathematics (STEM) Education Portfolio. www.whitehouse.gov/sites/default/files/microsites/ostp/ costem_federal_stem_education_portfolio_report.pdf (accessed 5 April 2013).

National Science Board (2012). Science and Engineering Indicators. www.nsf.gov/statistics/seind12/pdf/seind12.pdf (accessed 11 July 2013).

Pololi L, Cooper LA, Carr P (2010). Race, disadvantage and faculty experiences in academic medicine. J Gen Intern Med 25, 13631369.

Schroeder KB, Malhi RS, Smith DG (2006). Opinion: demystifying Native American genetic opposition to research. Evol Anthropol 15, 88-92.

Seymour E, Hewitt NM (1997). Talking about Leaving: Why Undergraduates Leave the Sciences, Boulder, CO: Westview Press.

Steele CM (1997). A threat in the air: how stereotypes shape intellectual identity and performance. Am Psychol 52, 613-629.

Tanner K, Allen D (2007). Cultural competence in the college biology classroom. CBE Life Sci Educ 6, 251-258.

U.S. Department of Health and Human Services (2005). Seventeenth Report: Minorities in Medicine: An Ethnic and Cultural Challenge for Physician Training, Rockville, MD. www.hrsa.gov/ advisorycommittees/bhpradvisory/cogme/Reports/seventeenthrpt .pdf (accessed 27 February 2013).

Villarejo J, Barlow AEL, Kogan D, Veazey BD, Sweeney JK (2008). Encouraging minority undergraduates to choose science careers: career paths survey results. CBE Life Sci Educ 7, 394-409. 